\title{
Stress among Urban and Rural High School Students and Related Factors
}

\author{
Mukta G. Sthavarmath and Manjula Patil* \\ Department of Human Development and Family Studies, College of Community Science, \\ University of Agricultural Sciences, Dharwad-580005, Karnataka, India \\ *Corresponding author
}

\section{A B S T R A C T}

\begin{tabular}{|l|}
\hline Key w or d s \\
$\begin{array}{l}\text { Stress, High school } \\
\text { students, Related } \\
\text { factors }\end{array}$ \\
\hline Article Info \\
\hline $\begin{array}{l}\text { Accepted: } \\
\text { 20 January } 2021 \\
\text { Available Online: } \\
\text { 10 February } 2021\end{array}$ \\
\hline
\end{tabular}

\section{Introduction}

Adolescence is a transition stage between childhood and adulthood and characterized by rapid physical changes and mental development. According to Ablard and Parker (2010) adolescence stage is defined as the time when individuals begin to function independently of their parents. It is the period of life when a child develops into an adult and generally seen from the age of 12 to 19 years. The modern world, which is said to be a world of achievement, is also a world of stress. One finds stress everywhere; whether it is within the family, business organization or any other social or economic activity. Stress is physiological and psychological imbalance. It arises due to the demands on a person and that person's inability to meet those demands. Stress in the students can be very taxing for 
the parents and the students themselves. Stress has been tightening its grip on the students, as they have to compete at every step of their academic career in this fast moving world.

Many adolescents as they undergo into student's life which is subjected to different kinds of stressors they have to face many academic demands.

For example, school examination, answering questions in the class, showing progress in school subjects, competing with other classmates, fulfilling teacher's and parent's academic expectations.

These demands may tax or exceed available resources of the students. As a consequence, they can be under stress. So need was felt to conduct a study on, stress among urban and rural high school students and related factors.

\section{Materials and Methods}

\section{Research Design}

The differential design was used to know the difference between urban and rural high school student's stress and 'chi square' analysis was employed to know the influence of gender, class, ordinal position and type of school on stress among urban and rural high school students.

\section{Population and Sample}

There were totally 98 high schools in urban locality and 188 high schools in rural locality of Dharwad taluk. Eight schools were randomly selected, within eight schools, about 4 per cent of 98 urban schools (four schools: 2 govt, 2 private aided) and 2 per cent of 188 rural schools (four schools: 2 govt, 2 private aided) were randomly selected for the study who were willing to participate and had cooperation for the study. The sample comprised of 480 high school students ( 240 boys and 240 girls) studying in $8^{\text {th }}, 9^{\text {th }}$ and $10^{\text {th }}$ classes of schools (government and private aided) situated at urban and rural localities of Dharwad taluk.

\section{Tools used for assessment}

The following tools were used to collect different information of the school children for the study.

\section{General information schedule}

The schedule was used to collect personal information such as name, gender, ordinal position, class, type of school and locale of school of high school students.

\section{Gender}

According to gender, students were classified as boys and girls.

Class

Based on their class, students were classified as $8^{\text {th }}, 9^{\text {th }}$ and $10^{\text {th }}$ classes.

\section{Ordinal position}

On the basis of the birth order of the adolescents in family, they were grouped into two categories as First borns and Later borns $\left(2^{\text {nd }}\right.$ child onwards $)$

\section{Type of school}

On the bases of the type of the school of the subject, it was grouped into 2 categories as Government school and Private aided school

\section{Location}

On the basis of the location of school of the subjects, it was grouped into 2 categories as Urban and Rural. 


\section{Structured questionnaire on stressors}

Structured questionnaire on stressors developed by Targar (2009), the questionnaire consisted of 59 items and 8 areas of stressors like school stressors (4 items), parental stressors (7 items), personal stressors (19 items), peer stressors (5 items), external stressors (5 items), physiological stressors (7 items), socio-economic stressors (2items) and teacher stressors (10 items). For each item, 4 alternative answers are given like 4- extreme stress, 3- a lot of stress, 2- slight stress and 1no stress and scoring is done as follows

\section{Data collection procedures}

For the present study, high schools were randomly selected and the Heads of the schools were contacted and permission was taken for conducting the study. Twenty students (both boys and girls) each from $8^{\text {th }}$, $9^{\text {th }}$ and $10^{\text {th }}$ classes were selected randomly. The concerned class students were approached and explained about the study so as to seek their honest answers.

The questionnaires were distributed to respective class students with right instructions. It took nearly one hour of 4 visits for the completion of all questionnaires for all selected classes. The filled questionnaires were collected and the doubts were cleared on the spot by the interviewer.

\section{Statistical analysis}

Frequency and percentages were used to interpret the gender, ordinal position, class, type of school and stress among urban and rural high school students. t-test was used to know the differences in stress among urban and rural areas and Chi-square was used to know the influence of gender, ordinal position, class, type of school on stress among urban and rural high school students.

\section{Results and Discussion}

Distribution of urban and rural high school students by personal characteristics

Results on distribution of students according to personal characteristics such as gender, ordinal position, class and type of school are presented in table 1 . With regard to gender, among 480 students, 50.62 per cent of students were girls and 49.16 per cent of students were boys. In urban locality, 55 per cent of students were girls and 45 per cent of students were boys. In rural 46.66 per cent of students were girls and 53.33 per cent of students were boys. With regard to ordinal position, in urban locality, majority (60.83\%) were later borns and 39.16 per cent were first borns. In rural locality, 54.16 per cent were later borns and 45.83 per cent were first borns. In total sample 57.50 were later borns and 42.5 per cent were first borns. Among total students, they were equally distributed among $8^{\text {th }}, 9^{\text {th }}$ and $10^{\text {th }}$ classes $(33.33 \%)$ and in both urban and rural localities (50\%). With respect to type of school, equal numbers of students were distributed in Government and private aided schools $(50 \%)$ and urban and rural localities (50\%).With respect to locale, students were equally distributed among urban and rural localities (50\%).

\section{Stressors among urban and rural high school students}

The differences in stressors and association and difference between stress among urban and rural high school students is presented in table 2 and 3. It was observed that, in urban locality, the highest mean (38.12) belonged to personal stressors followed by teacher stressors (17.24) and parental stressors (14.08). The least mean (6.39) belonged to socio-economic stressors. In rural locality also, the highest mean (31.73) personal, parental, familial) belonged to personal 
stressors followed by school stressors (17.27) and external stressors (13.54). The least mean (6.37) belonged to parental stressors. On statistical analysis significant difference found between urban and rural high school students on school, parental, personal, peer, external and teacher stressors at 0.01 level. Only with physiological stressors and socio-economic stressors not found significant difference. Paul and Damodaran (2016) have expressed similar opinion regarding the various characteristics responsible for causing stress besides concern about academic ability and scheduling classes. As per Okwara-Kalu (2014) some of the significant sources of stress included academic, intra-personal and environmental.

The results of table 3 showed the association and difference between stress level and locality of high school students. It was found that, in urban locality, majority $(47.91 \%)$ of students were in high level of stress followed by medium level of stress $(31.25 \%)$ and 20.83 per cent of students belonged to low level of stress. In rural locality, the same trend was followed that, 45.83 per cent of students were in high level of stress followed by medium level $(29.58 \%)$ and 24.58 per cent of students were in low level of stress. When both urban and rural localities considered, 49.79 per cent of students were in high level of stress followed by medium level $(26.87 \%)$ and 23.33 per cent of students belonged to low level of stress. On statistical analysis the 'chi square' value was found to be significant at 0.01 level. The mean score of rural students with regard to level of stress was found to be high (163.78) compared to mean score of urban locality students (143.25) and ' $t$ ' value was found to be significant between stress and locality. Similar results were reported by Kadapatti (2017) that, there was significant difference found between urban and rural areas of students in stress levels. However, in the present study, the rural students found to had more stress. It appears rural students will be facing extra pressure to perform as a key element of the family's drive to promote their social and economic status in comparison to their urban counterparts as reported by $\mathrm{Ai}$ Qiang et al., (2014).

\section{Influence of related factors on stress among urban and rural high school students}

Results of table 4 shows the association between stress and gender of urban and rural high school students which revealed that, in urban locality, majority of boys were under high level of stress (48.14\%) followed by medium level of stress (35.18\%) and 16.66 per cent boys had low level of stress. In case of girls, majority were in high level of stress $(47.72 \%)$ followed by medium level of stress $(28.03 \%)$ and 24.24 per cent girls were in low level of stress. The statistical analysis revealed that, there was a significant association found between gender and stress among urban high school students at 0.05 level. In rural locality, with regards to boys majority of them were under high level of stress (53.12\%) followed by low level of stress (31.25\%) and 21.09 per cent boys had medium level of stress. With regard to girls it was found that, majority were in high level of stress $(50 \%)$ followed by medium level of stress (24.10\%) and 19.64 per cent girls were in low level of stress. The 'chi square' analysis showed a significant association $\left(\chi^{2}=21.12\right)$ between gender and stress among rural high school students at 0.01 level. Results of the studies conducted by Rajkumar et al., (2012), Ai-qiang et al., (2014) and Solomon et al., (2014) reported significant association found between gender and stress among students.

Association between ordinal position and stress among urban and rural high school students

Results of table 5 shows the association between stress and ordinal of urban and rural 
high school students which revealed that, in urban as well as in rural localities, most of the first borns students were in high stress when compared to later borns students but there was no significant association found. Similar results reported by the Rajkumar et al., (2012) and Ai-qiang et al., (2014) that, there was no association found between the stress and ordinal position of secondary school students.

\section{Association between class and stress among} urban and rural high school students

The results on association between class and stress among urban and rural high school students is presented in table 6. In urban locality, among $8^{\text {th }}$ class students, majority of them $(36.25 \%)$ belonged to low level of stress followed by high level of stress $(35.00 \%)$ and 28.75 per cent of students were under medium level of stress. Among $9^{\text {th }}$ class students, majority of them were under medium level of stress $(47.50 \%)$ followed by high level of stress $(38.75 \%)$ and 15 per cent of students were under low level of stress. Among $10^{\text {th }}$ class students highest percentage of them (70\%) belonged to high level of stress followed by medium level of stress $(17.50 \%)$ and 11.25 per cent of students were under low level of stress. The 'chi square' analysis showed a significant association $\left(\chi^{2}=32.97\right)$ between class and stress at 0.01 level of significance.

In rural locality, it was found that, among $8^{\text {th }}$ class students, most of them $(47.50 \%)$ belonged to low level of stress followed by medium level of stress $(27.50 \%)$ and 25 per cent of students were under high level of stress.

Among $9^{\text {th }}$ class students, majority of them were under high level of stress $(53.75 \%)$ followed by low level of stress $(25.00 \%)$ and 21.25 per cent of students were under medium level of stress. Among $10^{\text {th }}$ class students, highest percentage of them $(76.25 \%)$ belonged to high level of stress followed by medium level of stress $(18.75 \%)$ and only 5 per cent of them were under low level of stress. In total, $10^{\text {th }}$ class students were under high level of stress in both urban and rural localities. On analysis, results showed a highly significant association.

These results are in line with the results reported by Saini et al., (2010), Rajkumar et al., (2012) and Sarada et al., (2017) they stated that, stress was significantly higher among the $10^{\text {th }}$ class students compared to $9^{\text {th }}$ and $8^{\text {th }}$ class students. It was a stark reminder of the tremendous pressure faced by the students with regards to their performance in the board examinations.

Association between type of school and stress among urban and rural high school students

The results in table 7 depict the association between type of school and stress among urban and rural high school students. In urban locality, 43.33 percent of government school students were under high level of stress followed by medium level of stress $(33.33 \%)$ and 23.33 per cent of students were under low level of stress.

It was found that majority of private aided school students were also under high level of stress $(52.50 \%)$ followed by medium level and low level of stress $(29.16 \%$ and $18.33 \%)$ respectively. In total, private aided school students were under high level of stress (Table 8).

Similarly, Saini et al., (2010) reported that, academic stress among the private school students was higher than government school students. The difference in terms of academic stress between the two groups of students was also statistically tested which was also found to be significant. 
Table.1

\begin{tabular}{|c|c|}
\hline Level of stress & Range of score \\
\hline Low stress & 87 and below \\
\hline Average stress & $88-143$ \\
\hline High stress & 144 and above \\
\hline
\end{tabular}

Table.2 Frequency distribution of urban and rural high school students by personal characteristics

\begin{tabular}{|c|c|c|c|c|c|c|c|}
\hline & & & & & & & $\mathrm{N}=480$ \\
\hline Personal & aracteristics & & & & & & \\
\hline & & $\mathbf{n}$ & $\%$ & n & $\%$ & $\mathbf{N}$ & $\%$ \\
\hline Gender & Girls & 132 & 55 & 112 & 46.66 & 244 & 50.62 \\
\hline & Boys & 108 & 45 & 128 & 53.33 & 236 & 49.16 \\
\hline Ordinal & $1^{\text {st }}$ born & 94 & 39.16 & 110 & 45.83 & 204 & 42.50 \\
\hline position & Later born & 146 & 60.83 & 130 & 54.16 & 276 & 57.50 \\
\hline Class of & $8^{\text {th }}$ class & 80 & 33.33 & 80 & 33.33 & 160 & 33.33 \\
\hline students & $9^{\text {th }}$ class & 80 & 33.33 & 80 & 33.33 & 160 & 33.33 \\
\hline & $10^{\text {th }}$ class & 80 & 33.33 & 80 & 33.33 & 160 & 33.33 \\
\hline Type of & Govt & 120 & 50 & 120 & 50 & 240 & 50.00 \\
\hline school & $\begin{array}{c}\text { Private } \\
\text { aided }\end{array}$ & 120 & 50 & 120 & 50 & 240 & 50.00 \\
\hline
\end{tabular}

Table.3 Differences in stressors among urban and rural high school students

\begin{tabular}{|c|c|c|c|c|c|}
\hline \multicolumn{9}{|c|}{ Areas of stressors } & \multicolumn{2}{|c|}{ Urban $\mathbf{( 2 4 0 )}$} & \multicolumn{2}{c|}{ Rural (240) } & t-value \\
\cline { 2 - 5 } & Mean & SD & Mean & SD & \\
\hline School & 7.84 & 2.31 & 17.27 & 7.69 & $\mathbf{8 . 6 9 * *}$ \\
\hline Parental & 14.08 & 3.85 & 6.37 & 2.97 & $\mathbf{5 . 2 2} * *$ \\
\hline Personal & 38.01 & 8.20 & 31.73 & 8.69 & $\mathbf{7 . 9 2} * *$ \\
\hline Peer & 9.68 & 3.22 & 8.36 & 2.57 & $\mathbf{7 . 5 5} * *$ \\
\hline External & 9.35 & 2.90 & 13.54 & 3.69 & $\mathbf{6 . 2 8} * *$ \\
\hline Teacher & 17.24 & 6.13 & 10.69 & 2.45 & $\mathbf{3 . 6 1} * *$ \\
\hline Physiological & 11.24 & 3.63 & 7.69 & 2.13 & 1.17 \\
\hline Socio-economic & 6.39 & 2.13 & 15.39 & 4.69 & 1.01 \\
\hline
\end{tabular}

** Significant at 0.01 level 
Table.4 Association and difference between stress among urban and rural high school students

\begin{tabular}{|c|c|c|c|c|c|c|c|c|c|c|c|}
\hline \multirow{4}{*}{ Locality } & & & & & & & & & \multirow{4}{*}{$\begin{array}{c}\chi^{2} \\
\text { value }\end{array}$} & \multicolumn{2}{|c|}{$\mathrm{N}=480$} \\
\hline & \multicolumn{8}{|c|}{ Levels of stress } & & Mean \pm SD & t-value \\
\hline & \multicolumn{2}{|c|}{ Low } & \multicolumn{2}{|c|}{ Medium } & \multicolumn{2}{|c|}{ High } & \multicolumn{2}{|c|}{ Total } & & & \\
\hline & $\mathbf{n}$ & $\%$ & $\mathbf{n}$ & $\%$ & $\mathbf{n}$ & $\%$ & $\mathbf{n}$ & $\%$ & & & \\
\hline Urban & 50 & 20.83 & 75 & 31.25 & 115 & 47.91 & 240 & 100 & \multirow[t]{3}{*}{$23.52 * *$} & $143.25 \pm 38.23$ & \multirow[t]{3}{*}{$6.95 * *$} \\
\hline Rural & 62 & 24.58 & 54 & 29.58 & 124 & 45.83 & 240 & 100 & & $163.78 \pm 41.23$ & \\
\hline Total & 112 & 23.33 & 129 & 26.87 & 239 & 49.79 & 480 & 100 & & $153 \pm 40.20$ & \\
\hline
\end{tabular}

** Significant at 0.01 level

Table.5 Association between gender and stress among urban and rural high school students

\begin{tabular}{|c|c|c|c|c|c|c|c|c|c|c|}
\hline & & & & & & & & & & 180 \\
\hline \multirow{3}{*}{ Level of stress } & \multicolumn{4}{|c|}{ Urban (240) } & \multirow{3}{*}{$\begin{array}{c}\chi^{2} \\
\text { value }\end{array}$} & \multicolumn{4}{|c|}{ Rural (240) } & \multirow{3}{*}{$\begin{array}{c}\chi^{2} \\
\text { value }\end{array}$} \\
\hline & \multicolumn{2}{|c|}{ Boys (108) } & \multicolumn{2}{|c|}{ Girls (132) } & & \multicolumn{2}{|c|}{ Boys (128) } & \multicolumn{2}{|c|}{ Girls (112) } & \\
\hline & $\mathbf{N}$ & $\%$ & $\mathbf{n}$ & $\%$ & & $\mathbf{n}$ & $\%$ & $\mathbf{n}$ & $\%$ & \\
\hline Low & 18 & 16.66 & 32 & 24.24 & \multirow{3}{*}{$19.31 *$} & 35 & 27.34 & 27 & 25.00 & \multirow{3}{*}{ 21.12** } \\
\hline Medium & 38 & 35.18 & 37 & 28.03 & & 32 & 25.00 & 22 & 19.64 & \\
\hline High & 52 & 48.14 & 63 & 47.72 & & 61 & 53.12 & 63 & 50 & \\
\hline
\end{tabular}

*Significant at 0.05 level

** Significant at 0.01 level

Table.6 Association between ordinal position and stress among urban and rural high school students

\begin{tabular}{|c|c|c|c|c|c|c|c|c|c|c|}
\hline & & & & & & & & & & 80 \\
\hline \multirow[t]{3}{*}{ Level of stress } & \multicolumn{4}{|c|}{ Urban (240) } & \multirow{3}{*}{$\begin{array}{c}\chi^{2} \\
\text { value }\end{array}$} & \multicolumn{4}{|c|}{ Rural (240) } & \multirow{2}{*}{$\begin{array}{c}\chi^{2} \\
\text { value }\end{array}$} \\
\hline & \multicolumn{2}{|c|}{$\begin{array}{l}\text { First born } \\
(94)\end{array}$} & \multicolumn{2}{|c|}{$\begin{array}{c}\text { Later born } \\
\qquad(146)\end{array}$} & & \multicolumn{2}{|c|}{$\begin{array}{c}\text { First born } \\
(110)\end{array}$} & \multicolumn{2}{|c|}{$\begin{array}{c}\text { Later born } \\
\text { (130) }\end{array}$} & \\
\hline & $\mathbf{N}$ & $\%$ & $\mathbf{n}$ & $\%$ & & $\mathbf{n}$ & $\%$ & $\mathbf{n}$ & $\%$ & \multirow[t]{4}{*}{6.03} \\
\hline Low & 17 & 18.08 & 33 & 22.60 & \multirow{3}{*}{2.17} & 24 & 21.81 & 38 & 29.23 & \\
\hline Medium & 24 & 36.17 & 51 & 34.93 & & 13 & 29.09 & 41 & 31.53 & \\
\hline High & 53 & 56.38 & 62 & 42.46 & & 73 & 66.36 & 51 & 39.23 & \\
\hline
\end{tabular}


Table.7 Association between class and stress among urban and rural high school students

\begin{tabular}{|c|c|c|c|c|c|c|c|c|c|c|c|c|c|c|}
\hline \multirow{4}{*}{$\begin{array}{c}\text { Level of } \\
\text { stress }\end{array}$} & \multirow{2}{*}{\multicolumn{6}{|c|}{ Urban (240) }} & \multirow{4}{*}{$\begin{array}{c}\chi^{2} \\
\text { value }\end{array}$} & \multirow{2}{*}{\multicolumn{6}{|c|}{ Rural (240) }} & \multirow{4}{*}{$\begin{array}{c}\chi^{2} \\
\text { value }\end{array}$} \\
\hline & & & & & & & & & & & & & & \\
\hline & \multicolumn{2}{|c|}{$\begin{array}{c}8^{\text {th }} \text { class } \\
(80)\end{array}$} & \multicolumn{2}{|c|}{$\begin{array}{c}9^{\text {th }} \text { class } \\
(80)\end{array}$} & \multicolumn{2}{|c|}{$\begin{array}{c}10^{\text {th }} \text { class } \\
(80)\end{array}$} & & \multicolumn{2}{|c|}{$\begin{array}{c}8^{\text {th }} \text { class } \\
(\mathbf{8 0})\end{array}$} & \multicolumn{2}{|c|}{$\begin{array}{c}9^{\text {th }} \text { class } \\
(80)\end{array}$} & \multicolumn{2}{|c|}{$\begin{array}{l}10^{\text {th }} \text { class } \\
(80)\end{array}$} & \\
\hline & $\mathbf{N}$ & $\%$ & $\mathbf{n}$ & $\%$ & $\mathbf{n}$ & $\%$ & & $\mathbf{n}$ & $\%$ & $\mathbf{n}$ & $\%$ & $\mathbf{n}$ & $\%$ & \\
\hline Low & 28 & 35.00 & 12 & 15.00 & 10 & 12.50 & \multirow{3}{*}{$12.97 * *$} & 27 & 33.75 & 23 & 28.75 & 12 & 15.00 & \multirow{3}{*}{$14.67 * *$} \\
\hline Medium & 23 & 28.75 & 38 & 47.50 & 14 & 17.50 & & 25 & 31.25 & 14 & 17.50 & 15 & 18.75 & \\
\hline High & 29 & 36.25 & 30 & 37.50 & 56 & 70 & & 28 & 35.00 & 43 & 53.75 & 53 & 66.25 & \\
\hline
\end{tabular}

** Significant at 0.01 level

Table.8 Association between type of school and stress among urban and rural high school students

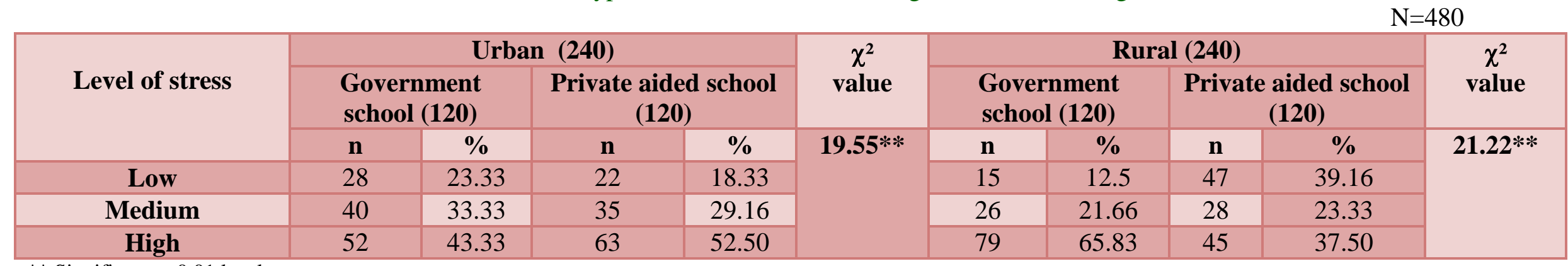

** Significant at 0.01 level 
With regard to rural locality, it was found that, majority (65.83) of government school students were prone to high level of stress followed by medium level of stress $(21.66 \%)$ and 12.5 per cent of students were under low level of stress. Among private aided school students, 39.16 per cent students were under low level of stress followed by high level of stress $(37.50 \%)$ and 23.33 per cent of students were prone to medium level of stress. In total, Government school students were under high level of stress. However on statistical analysis the results was found to be statistically significant association between type of school and stress among both urban and rural high school students at 0.01 level. Similar results have been reported by Rajkumar et al., (2012) and Ghosh (2016) who also found the significant association between level of stress and type of school.

The present study focused on influence of related factors on stress among urban and rural high school students. Majority of urban and rural high school students were under high level of stress. Girls were more prone to stress and higher the class indicated the high level of stress. When compared to government and private school students, in urban locality, private aided school students were under more stress compared government school students and in contrast, in rural locality, government school students were in high level of stress compared to private aided school students. So, the immediate need for counseling programmes and remedial measures such as such as yoga, meditation and participation in some recreational activities were needed to reduce the stress among high school students.

\section{References}

Ablard, K.E. and Parker W. D., 2010, Parent's achievement goal perfectionism in their academically talented children. J. Youth Adolescence., 26(6): 651-667.

Ai-qiang, S., Rao, C. and Oyeesiie, R., 2014, Educational stress among Chinese adolescents: individual, family, school and peer influences. Ind. J. Ped., 76: 495-499.

Ghosh, S.D., 2016, Academic stress among government and private high school students. Int J. Ind. Psych., 3: 1-7.

Kadapatti, M., 2017, Prevalence of academic stress among students. Int. J. H.Sc., 3(3): 461463.

Okwara-Kalu., Akande, J.A. and Olowonirejuaro, A.O., 2014, A study of level and sources of stress among secondary school students. J. Res. Method Edu., 4(5): 32-36.

Paul, V. and Damodaran, D.K., 2016, Stress management among adolescents. The Int. J. Ind. Psych., 3(1): 104-11.

Rajkumar, M., Stevensen, J. and Julie, A., 2012, Anxiety and depression in academic performance: An exploration of the mediating factors of worry and working memory. School Psych. Int., 33: 433-449.

Saini, N.K., Bhasin, S.K. and Sharmal, R., 2010, Depression, anxiety and stress among adolescent students belonging to affluent families: A school based study. Ind. J. Paed., 77: 161-165.

Sarada, M., 2017, The effect of anxiety and emotional intelligence on students' learning process. J. Edu. Soc. Policy., 1(2): $115-122$.

Solomon, A.O., Adom, A.E. and Emmukia, F.K., 2014, Perceived stress and academic performance of senior high school students in western region, Ghana. Business Social Sci., 2(11): 88-101.

Targar Shilpa., (2009), Stressors among the students of high school, Ms.c Thesis, University of agricultural sciences, Dharwad; Karnataka.

\section{How to cite this article:}

Mukta G. Sthavarmath and Manjula Patil. 2021. Stress among Urban and Rural High School Students and Related Factors. Int.J.Curr.Microbiol.App.Sci. 10(02): 2760-2768.

doi: https://doi.org/10.20546/ijcmas.2021.1002.305 